\title{
СРАВНИТЕЛЬНЫЙ АНАЛИЗ КЛИНИЧЕСКИХ РЕЗУЛЬТАТОВ ЛЕЧЕНИЯ ДОБРОКАЧЕСТВЕННОЙ ГИПЕРПЛАЗИИ ПРОСТАТЫ РАЗЛИЧНЫМИ ХИРУРГИЧЕСКИМИ МЕТОДАМИ
}
COMPARATIVE ANALYSIS OF CLINICAL RESULTS OF BENIGN PROSTATIC HYPERPLASIA TREATMENT WITH VARIOUS SURGICAL METHODS

\author{
V. Bychkovskih \\ A. Vasil'kov \\ V. Orlov \\ A. Milyutin \\ B. ZHeleznyakov
}

Summary. The results of treatment of benign prostatic hyperplasia (BPH) with new and traditional surgical methods were studied in the urology Department of the Road clinical hospital at the station «Chelyabinsk» of JSC «Russian Railways». The main groups were patients operated with new methods of bipolar transurethral resection (BTUR - 38 people) and prostate enucleation (TUEB - 35). For comparison, we selected statistically comparable groups of patients operated by the methods of monopolar transurethral resection (MTUR -39 patients) and open transvesical prostatectomy (OPE - 37), which were used in the Department earlier before the introduction of new methods. The choice of the surgical method was determined by the volume of $\mathrm{BPH}-$ up to $80 \mathrm{~cm} 3$ used BTUR (previously MTUR), over $80 \mathrm{~cm} 3$ - TUEB (previously OPE). The results of TUEB vs OPE has $2-3$ fold reduction in volume of blood loss during surgery, duration of postoperative bladder catheterization, frequency of intraoperative, early hemorrhagic and infectious complications and length of stay of patients in hospital. BTUR vs MTUR showed the possibility of a significant reduction in blood loss and surgical injuries during surgery, as well as early complications of an infectious and inflammatory nature. The clinical effectiveness in terms of the frequency of complications, repeated surgical interventions and dynamics of urological indicators was the best for BTUR and TUEB at 1 month and statistically similar at 6 months after surgery. Therefore, the introduction of new bipolar methods of transurethral surgery can speed up the recovery period, reduce the cost of hospitalization and improve the quality of surgical care for BPH.
\end{abstract}

Keywords: benign prostatic hyperplasia, bipolar transurethral resection and enucleation of the prostate.
Бычковских Владимир Анатольевич

Врач-уролог, НУЗ «Дорожная клиническая больнича на ст. Челябинск ОАО «РЖД», г. Челябинск

Васильков Александр Юрьевич

Врач-уролог, НУЗ «Дорожная клиническая больнича на ст. Челябинск ОАО «РЖД», г. Челябинск

Орлов Вадим Анатольевич

Врач-уролог, НУз «Дорожная клиническая больница на ст. Челябинск $О A O$ «РЖД», г. Челябинск v.orlov@dkb74.ru

Милютин Алексей Александрович

Врач-уролог, НУЗ «Дорожная клиническая больница на ст. Челябинск ОАО «РЖД», г. Челябинск

Железняков Богдан Александрович

Врач-уролог, НУз «Дорожная клиническая больнича на ст. Челябинск ОАО «РЖД», г. Челябинск

Аннотация. В урологическом отделении Дорожной клинической больницы на ст. Челябинск ОАО «РЖД» проведено изучение результатов лечения доброкачественной гиперплазии простаты (ДГП) новыми и традиционными хирургическими методами. Основные группы составили пациенты, оперированные новыми методами биполярной трансуретральной резекции (БТУР — 38 человек) и энуклеации простаты (ТУЭБ - 35). Для сравнения подобраны статистически сопоставимые группы пациентов, оперированных методами монополярной трансуретральной резекции (МТУР - 39 пациентов) и открытой чреспузырной простатэктомии (ОПЭ - 37), применявшихся в отделении ранее до внедрения новых методов. Выбор метода операции определялся объемами ДГП — до 80 см3 применяли БТУР (ранее МТУР), свыше 80 см3 - ТУЭБ (ранее ОПЭ). При сравнении результатов ТУэБ с ОПЭ установлено 2-3х кратное снижение объема кровопотери во время операции, сроков послеоперационной катетеризации мочевого пузыря, частоты интраоперационных, ранних геморрагических и инфекционных осложнений, а также сроков пребывания пациентов в стационаре. Сравнение БТУР с МТУР показало возможность значимого снижения кровопотери и хирургических травм во время операции, а также ранних осложнений инфекционно-воспалительного характера. Клиническая эффективность по частоте осложнений, повторных операций и динамике урологических показателей оказалась лучшей для БТУР и ТУЭБ через 1 месяц и статистически схожей через 6 месяцев после операции. Следовательно, внедрение новых биполярных методов трансуретральных операций позволяет ускорить восстановительный период, сократить расходы на госпитализацию и повысить качество хирургической помощи при ДГП.

Ключевые слова: доброкачественная гиперплазия предстательной железы, биполярная трансуретральная резекция и энуклеация простаты. 
$\Pi$ о данным мировой статистики 2/3 мужчин пенсионного возраста имеют клинические проявления доброкачественной гиперплазии простаты (ДГП) в разной степени выраженности симптомов нижних мочевыводящих путей (СНМП) $[4,5,18]$. Выраженность СНМП определяется по специально разработанной международной шкале оценки (IPSS), пороговым значением установлено 8 баллов, превышение которого требует активных методов лечения $[9,11]$.

Среди активных методов лечения ДГП в последние годы все чаще используются малоинвазивные хирургические техники, в том числе биполярная трансуретральная резекция и энуклеация простаты (БТУР и ТУЭБ) $[7,16,20]$. Их преимущества перед открытой простатэктомией (ОПЭ) и моноплярной трансуретральной резекцией простаты (МТУР), ранее активно используемой в эндохирургии ДГП, в настоящее время исследуются. Доказанными можно считать значительное сокращение кровопотери во время операции, сроков пребывания пациентов в стационаре, устранение риска ТУР-синдрома и электроожоговых травм, характерных для МТУР, а также возможность применения при осложненных формах ДГП и высоком анестезиологическом риске $[1,12,13,19]$. Для ТУЭБ также доказана ее альтернативность с результатами ОПЭ при ДГП большого и крупного размера (свыше $100 \mathrm{~cm}^{3}$ ) [10,14,17]. Многие урологи также отмечают более быстрое восстановление пациентов после биполярных трансуретральных операций, что позволяет сократить расходы на госпитализацию и медикаментозную коррекцию нарушений мочеиспускания после оперативного лечения на амбулаторном этапе $[6,15]$. Изучение клинической эффективности методов БТУР и ТУЭБ показало их сопоставимость с традиционными хирургическими пособиями (ОПЭ и МТУР) по частоте отсроченных осложнений функционального и обструктивного характера. При этом повторные операции для их коррекции проводятся реже, поскольку большинство проявлений СНМП удается купировать консервативными методами $[2,3,8]$.

Таким образом, широкое внедрение биполярной техники выполнения трансуретральных операций в хирургическую практику лечения ДГП является актуальной проблемой эндоурологии. В этой связи целью предпринятого исследования был сравнительный анализ клинических результатов новых и традиционных методов операций, применяемых для лечения ДГП.

\section{Материалы и метолы}

Новые методы трансуретральных эндоскопических операций с применением биполярной техники в хирургическом лечении ДГП используются в отделении урологии Дорожной клинической больницы на ст. Челябинск
ОАО «РЖД» с 2018 года. Операции выполняются при помощи биполярного резектоскопа, электрохирургического блока ESG-400 и съемных электродов для трансуретральной резекции и энуклеации. Электробезопасность биполярной техники обеспечивается минимально необходимой мощностью оборудования (не более $310 \mathrm{~W}$ для резекции и не более $120 \mathrm{~W}$ для коагуляции), что позволяет при одновременном выполнении резекции и гемостаза не превышать температуру ткани (в пределах 40-70), устраняя риск электроожоговых травм окружающих тканей и анатомических структур. Кроме того, в качестве ирриганта, в отличие от монополярной ТУР, применяется 0,9\% раствор $\mathrm{NaCl}$, обладающий высокой электропроводностью.

Для исследования отобраны пациенты с различным объемом ДГП, оперированные методом биполярной трансуретральной резекции (БТУР - 38 чел., средний объем простаты - 65,4 см $\left.{ }^{3}, \max -76, \min -42\right)$ и биполярной трансуретральной энуклеации простаты (ТУЭБ - 35 чел., средний объем - 128,5 см³, 230 / 90). Ранее в отделении для лечения ДГП с объемом до $80 \mathrm{~cm}^{3}$ использовали монополярную технику ТУР (МТУР), свыше $80 \mathrm{~cm}^{3}$ - открытую чреспузырную простатэктомию (ОПЭ). Для сравнения клинических результатов из архива историй болезни и протоколов операций отобраны пациенты со статистически сопоставимыми исходными параметрами. Результаты БТУР сравнивали с МТУР (39 чел., средний объем простаты - 58,3 см³, 71 / 45; р = 0,094), ТУЭБ - с ОПЭ (37 чел., 124,3 см 3 , $220 / 95 ; \mathrm{p}=$ 0,814). Средний возраст пациентов, отобранных для исследования, в группах БТУР / МТУР был 65,7 ( $p=0,745)$, в группах ТУЭБ / ОПЭ - 70,0 ( $p=0,902)$.

Сравнение проводили: по общим операционным результатам (время оперативного вмешательства, объем кровопотери и удаленной ткани, сроки послеоперационной катетеризации мочевого пузыря и пребывания в стационаре); по количеству осложнений во время и после операции в раннем и позднем периоде; по частоте повторных операций и динамике исходных урологических показателей через 1 и 6 месяцев после выписки из стационара (объем остаточной мочи по данным трансректального УЗИ, максимальная скорость мочеиспускания по данным урофлоуметрии, оценка выраженности простатических симптомов и качества жизни в связи с расстройством мочеиспускания по специальным шкалам (IPSS и QOL)).

Статистический анализ проводили с расчетом средних и интенсивных показателей (\% в группе) и ошибок средних и относительных величин. Оценка нормальности распределения в выборках пациентов показала возможность применения для подтверждения достоверности различий показателей параметрического t-критерия 
Таблица 1. Общие операционные результаты (средние показатели, $\mathrm{max} / \mathrm{min}$ )

\begin{tabular}{|c|c|c|c|c|c|c|}
\hline $\begin{array}{l}\text { Метод операции } \\
\text { Показатели }\end{array}$ & $\begin{array}{l}\text { БТУР } \\
(n=38)\end{array}$ & $\begin{array}{l}\text { MTYP } \\
(n=39)\end{array}$ & $\mathbf{P}$ & $\begin{array}{l}\text { ТУЭБ } \\
(n=35)\end{array}$ & $\begin{array}{l}\text { ОПЭ } \\
(n=37)\end{array}$ & $\mathbf{P}$ \\
\hline Время операции, мин & $57,6 \pm 3,06$ & $55,2 \pm 2,97$ & 0,575 & $95,3 \pm 4,01$ & $64,4 \pm 3,25$ & $0,010^{*}$ \\
\hline $\max$ & 105 & 92 & - & 138 & 125 & - \\
\hline $\min$ & 35 & 30 & - & 55 & 40 & - \\
\hline П/о катетеризация МП, дни & $1,9 \pm 0,56$ & $2,3 \pm 0,61$ & 0,628 & $2,5 \pm 0,65$ & $7,2 \pm 1,09$ & $<0,001^{*}$ \\
\hline $\max$ & 3 & 4 & - & 5 & 10 & - \\
\hline $\min$ & 1 & 1 & - & 2 & 5 & - \\
\hline П/о койко-день & $4,1 \pm 0,82$ & $5,6 \pm 0,95$ & 0,134 & $5,9 \pm 1,00$ & $10,3 \pm 1,30$ & 0,009 \\
\hline $\max$ & 7 & 9 & - & 8 & 13 & - \\
\hline $\min$ & 3 & 4 & - & 4 & 8 & - \\
\hline $\begin{array}{l}\text { Объем кровопотери при } \\
\text { операции, мл }\end{array}$ & $153,6 \pm 4,99$ & $310,1 \pm 7,05$ & $<0,001^{*}$ & $175,1 \pm 5,44$ & $396,7 \pm 8,08$ & $<0,001^{*}$ \\
\hline $\max$ & 250 & 450 & - & 350 & 600 & - \\
\hline $\min$ & 50 & 150 & - & 100 & 300 & - \\
\hline
\end{tabular}

* статистически значимые различия показателей $(p \leq 0,05)$.

Стьюдента. Уровень значимости различий для исследования определен 95\% ( $p \leq 0,05)$.

На основе расчетов по результатам предоперационного обследования пациентов определена статистическая сопоставимость сравниваемых групп, т.е. по всем исходным урологическим показателям различие было статистически не значимым ( $>>0,05)$. Количество осложненных форм ДГП (камни мочевого пузыря, эпицистостома, дивертикул, уретерогидронефроз) и сопутствующих заболеваний и состояний (гипертоническая болезнь, постинфарктный кардиосклероз, аритмии, антикоагулянтная терапия, цереброваскулярные заболевания, сахарный диабет) в сравниваемых группах пациентов было статистически равным ( $p>0,05)$.

\section{Результаты исслеАования}

Сравнение общих операционных показателей между группами пациентов, оперированных методами БТУР и МТУР, показало статистически равное среднее время оперативного вмешательства и средней длительности послеоперационной катетеризации мочевого пузыря, таблица 1. Сроки пребывания в стационаре были меньшими для БТУР (в среднем 4,1 дня против 5,6 дней при МТУР), но без статистического подтверждения различия показателей $(p=0,134)$. При этом средний объем кровопотери во время БТУР был в 2 раза меньшим - 153,6 мл $(p<0,001)$.
Средняя продолжительность ТУЭБ была в 1,5 раза больше, чем ОПЭ ( $p=0,010)$, но все остальные операционные показатели статистически отличались в пользу ТУЭБ - кровопотеря была в 2,3 раза меньше ( $<<0,001)$, сроки послеоперационной катетеризации - в 2,9 раза $(\mathrm{p}<0,001)$, госпитализации - в $-1,8$ раза $(\mathrm{p}=0,009)$.

По частоте осложнений оперативного лечения из-за небольшого количества наблюдений в группах статистическое различие подтверждено только для раннего послеоперационного периода группы ТУЭБ, таблица 2. В то же время важно отметить, что интраоперационно массивное кровотечение возникло только при чреспузырной простатэктомии (2 случая / 5,4\% в группе) и было связано с повреждением дорсального венозного комплекса.

С целью купирования кровотечения выполнено прошивание дорсального венозного комплекса. Интраоперационно и в раннем послеоперационном периоде потребовались трансфузии эритроцитарной массы и свежезамороженной плазмы. Данные осложнения привели к пролонгации сроков дренирования мочевого пузыря до 7 и 8 послеоперационных суток, и соответственно общих сроков госпитализации до 12 и 13 дней. В раннем периоде после ОПЭ наблюдались еще 3 случая кровотечения, связанные с несостоятельностью швов, эти случаи не потребовали гемотрансфузии и были купированы консервативно. После МТУР также наблюдался 
Таблица 2. Осложнения оперативного лечения (\% в группе)

\begin{tabular}{|c|c|c|c|c|c|c|}
\hline $\begin{array}{l}\text { Метод операции } \\
\text { Показатели }\end{array}$ & $\begin{array}{l}\text { БТУР } \\
(n=38)\end{array}$ & $\begin{array}{l}\text { MTУP } \\
(n=39)\end{array}$ & $\mathbf{P}$ & $\begin{array}{l}\text { ТУЭБ } \\
(n=35)\end{array}$ & $\begin{array}{l}\text { ОПЭ } \\
(n=37)\end{array}$ & $\mathbf{P}$ \\
\hline $\begin{array}{l}\text { В ходе операции всего, в том } \\
\text { числе: }\end{array}$ & 0,0 & $5,1 \pm 3,53$ & 0,151 & $5,7 \pm 3,92$ & $10,8 \pm 5,10$ & 0,432 \\
\hline кровотечение & 0,0 & 0,0 & 1,000 & 0,0 & $5,4 \pm 3,72$ & 0,152 \\
\hline конверсия в ОПЭ & 0,0 & 0,0 & 1,000 & $2,9 \pm 2,82$ & - & - \\
\hline гемотрансфузия & 0,0 & 0,0 & 1,000 & 0,0 & $5,4 \pm 3,72$ & 0,152 \\
\hline хирургическая травма & 0,0 & $5,1 \pm 3,53$ & 0,151 & $2,9 \pm 2,82$ & 0,0 & 0,316 \\
\hline $\begin{array}{l}\text { Ранний период всего, } \\
\text { в том числе: }\end{array}$ & $2,6 \pm 3,60$ & $12,8 \pm 5,35$ & 0,091 & $5,7 \pm 3,92$ & $32,4 \pm 7,70$ & $0,003^{*}$ \\
\hline кровотечение & $2,6 \pm 3,60$ & $5,1 \pm 3,53$ & 0,570 & $2,9 \pm 2,82$ & $13,5 \pm 5,62$ & 0,094 \\
\hline инфекционно-воспалительные & 0,0 & $7,7 \pm 4,27$ & 0,090 & $2,9 \pm 2,82$ & $18,9 \pm 6,44$ & $0,025^{*}$ \\
\hline $\begin{array}{l}\text { Поздний период всего, в том } \\
\text { числе: }\end{array}$ & $31,6 \pm 7,54$ & $38,5 \pm 7,79$ & 0,531 & $34,3 \pm 8,02$ & $37,8 \pm 7,97$ & 0,757 \\
\hline рубцовая деформация шейки МП & 0,0 & $2,6 \pm 2,53$ & 0,316 & $2,9 \pm 2,82$ & $5,4 \pm 3,72$ & 0,584 \\
\hline стриктура уретры & $2,6 \pm 3,60$ & $5,1 \pm 3,53$ & 0,570 & $2,9 \pm 2,82$ & 0,0 & 0,316 \\
\hline недержание мочи & $2,6 \pm 3,60$ & $2,6 \pm 2,53$ & 0,984 & $2,9 \pm 2,82$ & 0,0 & 0,316 \\
\hline $\begin{array}{l}\text { другие дизурические } \\
\text { расстройства }\end{array}$ & $26,3 \pm 7,14$ & $28,2 \pm 7,21$ & 0,850 & $25,7 \pm 7,39$ & $32,4 \pm 7,70$ & 0,531 \\
\hline Повторная операция & $2,6 \pm 3,60$ & $2,6 \pm 2,53$ & 0,984 & $2,9 \pm 2,82$ & $5,4 \pm 3,72$ & 0,584 \\
\hline
\end{tabular}

* статистически значимые различия показателей $(p \leq 0,05)$.

Таблица 3. Динамика урологических показателей (средние показатели)

\begin{tabular}{|c|c|c|c|c|c|c|}
\hline $\begin{array}{l}\text { Метод операции } \\
\text { Показатели }\end{array}$ & $\begin{array}{l}\text { БТУР } \\
(n=38)\end{array}$ & $\begin{array}{l}\text { МТУР } \\
(n=39)\end{array}$ & $\mathbf{P}$ & $\begin{array}{l}\text { ТУЭБ } \\
(n=35)\end{array}$ & $\begin{array}{l}\text { ОПЭ } \\
(n=37)\end{array}$ & $\mathbf{P}$ \\
\hline \multicolumn{7}{|l|}{ Перед операцией } \\
\hline Объем простаты, см³ & $65,4 \pm 3,26$ & $58,3 \pm 2,95$ & 0,094 & $128,5 \pm 3,02$ & $124,3 \pm 2,95$ & 0,814 \\
\hline Объем остаточной мочи, PVR, мл & $202,3 \pm 5,14$ & $197,5 \pm 5,62$ & 0,123 & $308,7 \pm 7,22$ & $310,4 \pm 7,14$ & 0,868 \\
\hline $\begin{array}{l}\text { Скорость потока } \\
\text { мочи, Qmax, мл/сек }\end{array}$ & $10,6 \pm 1,31$ & $11,2 \pm 1,34$ & 0,750 & $8,3 \pm 1,18$ & $8,7 \pm 1,20$ & 0,813 \\
\hline Балл по шкале IPSS & $25,5 \pm 2,03$ & $24,7 \pm 1,99$ & 0,779 & $28,6 \pm 2,20$ & $29,1 \pm 2,09$ & 0,872 \\
\hline Балл по шкале QOL & $4,2 \pm 0,83$ & $4,3 \pm 0,83$ & 0,932 & $5,3 \pm 0,95$ & $5,1 \pm 0,92$ & 0,880 \\
\hline \multicolumn{7}{|l|}{ Через 1 мес. после операции } \\
\hline Объем простаты, см³ & $30,4 \pm 2,22$ & $29,3 \pm 2,17$ & 0,724 & $33,5 \pm 2,38$ & $34,3 \pm 2,37$ & 0,813 \\
\hline Объем остаточной мочи, PVR, мл & $22,3 \pm 1,90$ & $25,5 \pm 2,02$ & 0,253 & $30,7 \pm 2,28$ & $42,4 \pm 2,64$ & $0,001^{*}$ \\
\hline $\begin{array}{l}\text { Скорость потока мочи, Qmax, } \\
\text { мл/сек }\end{array}$ & $17,6 \pm 1,69$ & $18,2 \pm 1,71$ & 0,803 & $20,3 \pm 1,85$ & $16,7 \pm 1,66$ & 0,152 \\
\hline Балл по шкале IPSS & $5,5 \pm 0,94$ & $6,7 \pm 1,04$ & 0,395 & $6,0 \pm 1,01$ & $10,1 \pm 1,29$ & $0,015^{*}$ \\
\hline Балл по шкале QOL & $2,2 \pm 0,60$ & $2,3 \pm 0,61$ & 0,907 & $2,3 \pm 0,62$ & $4,7 \pm 0,88$ & $0,029^{*}$ \\
\hline \multicolumn{7}{|l|}{ Через 6 мес. после операции } \\
\hline Объем простаты, см ${ }^{3}$ & $19,2 \pm 1,76$ & $20,6 \pm 1,82$ & 0,582 & $21,1 \pm 1,89$ & $23,4 \pm 1,96$ & 0,401 \\
\hline Объем остаточной мочи, PVR, мл & $3,0 \pm 0,70$ & $3,7 \pm 0,77$ & 0,502 & $5,3 \pm 0,95$ & $5,1 \pm 0,92$ & 0,880 \\
\hline $\begin{array}{l}\text { Скорость потока } \\
\text { мочи, Qmax, мл/сек }\end{array}$ & $23,4 \pm 1,95$ & $22,5 \pm 1,90$ & 0,742 & $23,8 \pm 2,01$ & $24,4 \pm 2,00$ & 0,833 \\
\hline Балл по шкале IPSS & $4,3 \pm 0,84$ & $4,8 \pm 0,88$ & 0,681 & $4,6 \pm 0,88$ & $5,0 \pm 0,91$ & 0,753 \\
\hline Балл по шкале QOL & $1,2 \pm 0,44$ & $1,3 \pm 0,46$ & 0,875 & $1,9 \pm 0,57$ & $2,2 \pm 0,60$ & 0,718 \\
\hline
\end{tabular}

\footnotetext{
* статистически значимые различия показателей $(p \leq 0,05)$.
} 
1 случай кровотечения (2,9\%), обусловленный интраоперационной травмой капсулы простаты, для купирования проводили гемотрансфузию эритроцитарной массы в объеме 2x доз. По биполярным трансуретральным операциям геморрагические осложнения интраоперационно отсутствовали, в раннем периоде наблюдались единично, не были интенсивными и не требовали переливания компонентов крови и повторных операций.

Инфекционно-воспалительные осложнения после БТУР не наблюдались, в группе МТУР - 3 случая (7,7\%; p = 0,090), ТУЭБ - 1 случай орхоэпидидимита (2,9\%), тогда как в группе ОПЭ - 7 случаев $(18,9 \% ; p=0,025)$.

Среди отсроченных послеоперационных осложнений независимо от оперативного метода наиболее часто встречались дизурические расстройства, которые проявлялись учащением мочеиспускания, императивными позывами к мочеиспусканию у пациентов после чреспузырной аденомэктомии в 12 случаях (32,4\%), у пациентов после трансуретральных пособий в 10-11 случаях (26,3\% БТУР; 28,2\% МТУР; 25,7\% ТУЭБ). С целью их купирования на срок 3 месяца назначалась консервативная терапия по схеме: «Везикар»10 мг по 1 капс. 1 раз в день + «Омник» 0,4 по 1 капс. 1 раз в день.

Случаи недержания мочи и рубцовых осложнений во всех группах были единичными либо отсутствовали без значимого статистического различия по методам операций ( $p>0,05)$. В частности, после трансуретральных операций было по одному случаю стрессового недержания мочи, для купирования пациентам рекомендован приём препаратов группы М-холинолитиков («Везикар» по 1 капс. 1 раз в день) длительностью 3 месяца и выполнение упражнения Кегеля. Рубцовая деформация шейки мочевого пузыря наблюдалась в 2x случаях (5,4\%) после аденомэктомии и требовала проведения ТУР шейки мочевого пузыря. В рекомендациях при выписке пациентов после трансуретральной коррекции деформации шейки пузыря назначалась «Лонгидаза» по 1 свече через день № 10 и после 2-х дневного перерыва продолжение курса препарата (№ 10). Непротяженная стриктура бульбозного отдела уретры возникла у одного пациента группы БТУР, $2 x-$ группы МТУР и у одного после ТУЭБ. С целью устранения обструкции проводились реконструктивные операции в объеме анастомотической пластики уретры через 6 месяцев после трансуретрального пособия. По частоте повторных (реконструктивных) операций межгруппового различия не наблюдалось ( $p>0,05)$.

Для оценки эффективности биполярных трансуретральных пособий в лечении ДГП различных размеров провели анализ динамики урологических показателей через 1 и 6 мес. после операций, таблица 3. Через 1 ме- сяц на контрольном обследовании для всех исследуемых групп установлено значимое сокращение объема простаты (в среднем в 2,2-3,8 раза) в сравнении с дооперационными измерениями, через 6 месяцев среднее значение данного показателя достигло возрастной нормы, не превышая $23 \mathrm{~cm}^{3}$. Средняя скорость мочеиспускания во всех группах пациентов в течение периода наблюдения плавно нарастает, средний объем остаточной мочи (PVR) через 1 месяц после операций десятикратно уменьшается и приближается к нулю по окончанию полугодия.

Такое же прогрессивное снижение наблюдается по баллам шкал оценки выраженности простатических симптомов IPSS и качества жизни в связи с расстройством мочеиспускания QOL. При этом месячная динамика значений PVR, IPSS и QOL в группе ТУЭБ более выражена, чем в группе ОПЭ, что обеспечило достоверное межгрупповое различие ( $p=0,001 ; p=0,015 ; p=0,029$ ). Через 6 месяцев разность показателей между группами БТУР - МТУР и ТУЭБ - ОПЭ не определяется, что демонстрирует равную клиническую эффективность для сравниваемых методов операций.

\section{Зак^ючение}

Биполярная модификация трансуретральной резекции и энуклеации простаты является эффективной и безопасной методикой оперативного лечения ДГП любого размера. Это подтвердили как общие клинические результаты, свидетельствующие при сравнении со стандартными методами операции о существенном снижении интраоперационной кровопотери, послеоперационных сроков катетеризации мочевого пузыря и пребывания в стационаре, так и минимальное количество геморрагических и инфекционно-воспалительных осложнений в раннем периоде после операций. Отсутствие статистической разности по частоте повторных хирургических вмешательств и полугодовой динамике урологических показателей демонстрирует альтернативность БТУР и МТУР, а также ТУЭБ и ОПЭ в отдаленной перспективе. При этом месячная динамика для биполярных эндохирургических методов более выражена, то есть наблюдается более быстрое восстановление пациентов после операций, что имеет важное экономическое значение для урологического стационара и пациентов.

\section{Выво $\triangle \mathrm{b}$}

Биполярные трансуретральные пособия можно считать новым стандартом оперативного лечения ДГП любого размера, их широкое внедрение позволит повысить качество хирургической помощи пациентам данного профиля. 


\section{ЛИТЕРАТУРА}

1. Гордеев В.В., Антонов А. Г., Писаренко М. Ю., Маршев С. В., Масальцева Н. А. Биполярная трансуретральная резекция в физиологическом растворе при осложненных формах доброкачественной гиперплазии предстательной железы // Тихоокеанский медицинский журнал. 2016. № 1. С. 79-81.

2. Данилов В.В., Осинкин К. С., Данилов В. В., Севрюков Ф. А. Альфа1-адреноблокаторы и гиперактивность детрузора у пациентов с аденомой предстательной железы // Вопросы урологии и андрологии. 2018. Т. 6. № 2. С. 49-53.

3. Иващенко В. А., Дюсюбаев А. А. Диагностика и медикаментозная коррекция симптомов нижних мочевых путей после ТУР доброкачественной гиперплазии предстательной железы // Медицинский вестник Башкортостана. 2013. Т. 8. № 2. С. 62-66.

4. Севрюков Ф. А., Камаев И. А., Малинина 0.Ю., Елина Ю. А., Гриб М. Н., Перевезенцев Е. А. Возрастные особенности заболеваемости мужчин болезнями мочеполовой системы // Медицинский альманах. 2011. № 4 (17). С. 21-23.

5. Севрюков Ф. А., Камаев И. А., Малинина 0. Ю., Гриб М. Н., Перевезенцев Е. А. Социальный статус пациентов, страдающих доброкачественной гиперплазией предстательной железы // Общественное здоровье и здравоохранение. 2011. № 1. С. 53-56.

6. Севрюков Ф. А., Малинина 0. Ю., Елина Ю. А. Особенности медицинского обеспечения пациентов с доброкачественной гиперплазией предстательной железы на этапе амбулаторно-поликлинической помощи // Медицинский альманах. 2011. № 1 (14). С. $25-27$.

7. Севрюков Ф. А., Малинина 0. Ю. Новые организационные технологии оказания медицинской помощи больным с доброкачественной гиперплазией предстательной железы // Социальные аспекты здоровья населения. 2012. Т. 23. № 1. С. 1-7.

8. Семенычев Д. В., Севрюков Ф. А., Сорокин Д.А., Карпухин И. В., Пучкин А. Б., Кочкин А. Д. Опыт применения биполярной вапорезекции предстательной железы (TUVRB) в лечении ДГПЖ // Экспериментальная и клиническая урология. 2014. № 2. С. 49-53.

9. Пушкарь Д. Ю., Раснер П. И., Харчилава Р. Р. Симптомы нижних мочевыводящих путей и доброкачественная гиперплазия предстательной железы / В кн.: Урология. Российские клинические рекомендации. ред. Аляев Ю. Г., Глыбочко П. В., Пушкарь Д. Ю. М.: Медфорум. 2017. С. $13-39$.

10. Chen S., Zhu L., Cai J., et al. Plasmakinetic enucleation of the prostate compared with open prostatectomy for prostates larger than 100 grams: A randomized noninferiority controlled trial with long-term results at 6 years // Eur. Urology. 2014. № 66. P. 284-291.

11. EAU guidelines on the treatment and follow-up of nonneurogenic male lower urinary tract symptoms including benign prostatic obstruction / Oelke M., Bachmann A., Descazeaud A., et al. // Eur. Urology. 2013; 64(1). P. 118-140.

12. Geavlete B., Bulai C., Ene C., at al. Bipolar vaporization, resection, and enucleation versus open prostatectomy: optimal treatment alternatives in large prostate cases? // J. Endourologie. 2015. № 29(3). P. 323-31.

13. Gilling P. TURP remains a safe and effective alternative for benign prostatic hyperplasia (BPH) surgery // BJU Int. 2014. № 113(1). P. 5-6.

14. Li M., Qiu J., Hou Q. et al. Endoscopic enucleation versus open prostatectomy for treating large benign prostatic hyperplasia: a meta-analysis of randomized controlled trials // PLoS One 2015. № 10(3): e0121265.

15. Mathieu R., Lebdai S., Cornu J. N., et al. Perioperative and economic analysis of surgical treatments for benign prostatic hyperplasia: A study of the French committee on LUT // Progrès en Urologie. 2017. Vol. 27 (6). P. 362-368.

16. Nakagava K. A new minimally invasive medical treatment for prostatic hyperplasia: its current situation and actual practice of the operation; TUEB // Urology View. 2007. Vol. 5. P. 95-97.

17. Rao J. M., Xiao H. J., Ren Y.X., et al. Did prostate size affect the complication and outcome of plasmakinetic enucleation of the prostate? // International Urology and Nephrology. 2014. № 46(11). P. 2063-70.

18. Roehrborn, C. G. Benign Prostatic Hyperplasia: Etiology, Pathophysiology, Epidemiology, and Natural History // Campbell-Walsh Urology. 10-th ed. 2012. P. 25702610.

19. Stucki P., Marini L., Mattei A., at al. Bipolar versus monopolar transurethral resection of the prostate: a prospective randomized trial focusing on bleeding complications // J. Urology. 2015. № 193(4). P. 1371-76.

20. Yu X., Elliott S. P., Wilt T. J., McBean A. M. Practice patterns in benign prostatic hyperplasia surgical therapy: the dramatic increase in minimally invasive technologies // J. Urology. 2008. № 180(1). P. 241-5.

( Бычковских Владимир Анатольевич, Васильков Александр Юрьевич, Орлов Вадим Анатольевич ( v.orlov@dkb74.ru ),

Милютин Алексей Александрович, Железняков Богдан Александрович.

Журнал «Современная наука: актуальные проблемы теории и практики» 